\title{
Erratum to: Postural control of typical developing boys during the transition from double-leg stance to single-leg stance
}

\author{
Kevin Deschamps ${ }^{1,2,3} \cdot$ Filip Staes $^{1} \cdot$ Kathelijne Peerlinck $^{4} \cdot$ Kristel Van Geet ${ }^{4}$. \\ Cedric Hermans $^{5}$ - Sebastien Lobet ${ }^{5,6}$
}

Published online: 4 February 2017

(C) Springer-Verlag Berlin Heidelberg 2017

Erratum to: Eur J Pediatr (2017) 176:273-278

DOI 10.1007/s00431-016-2829-0

The original version of this article unfortunately contains an error in the name of the authors. The first and family names were interchanged. The correct author names are now presented in the authorgroup.

The online version of the original article can be found at http://dx.doi.org/ 10.1007/s00431-016-2829-0.

Kevin Deschamps

kevin.deschamps@ faber.kuleuven.be; kevin.deschamps@ vinci.be; kevin.deschamps@arteveldehs.be

Kathelijne Peerlinck

kathelijne.peerlinck@kuleuven.be

Kristel Van Geet

krsitel.vangeet@kuleuven.be

Cedric Hermans

cedric.hermans@uclouvain.be

Sebastien Lobet

sebastien.lobet@uclouvain.be
1 Department of Rehabilitation Sciences-Musculoskeletal Rehabilitation Research Group, KULeuven, Tervuursevest 101, B-3001 Leuven (Heverlee), Belgium

2 Division of Podiatry, Institut D'Enseignement Supérieur Parnasse Deux-Alice, Avenue Mounier 84, B-1200 Bruxelles, Belgium

3 Department of Podiatry, Artevelde University College, Kantienberg 900 Ghent, Belgium

4 Department of Cardiovascular Sciences- Centre for Molecular and Vascular Biology, KULeuven, Herestraat 49, box 911, 3000 Leuven, Belgium

5 Service d'hématologie, Cliniques Universitaires Saint-Luc, Avenue Hippocrate 10, 1200 Bruxelles, Belgium

6 Institut de Recherche Expérimentale et Clinique, Computer Assisted Robotic Surgery (CARS), Avenue Hippocrate 10, 1200 Bruxelles, Belgium 